\title{
MOTIVATIONAL ASPECTS REGARDING PARTICIPATION IN PHYSICAL EDUCATION CLASSES OF STUDENTS WITH PARTIAL MEDICAL EXEMPTION
}

\author{
Diana Consuela MITU ${ }^{1 *}$, Mircea NEAMȚU ${ }^{2}$, Maria TUDOR ${ }^{1}$, Iulian-Doru TUDOR ${ }^{1}$ \\ 1 "Carol Davila" University of Medicine and Pharmacy, Bucharest, Romania \\ ${ }^{2}$ National University of Physical Education and Sport, Bucharest, Romania \\ *Corresponding author: mitudiana@yahoo.com
}

DOI: https://doi.org/10.51267/icpesk2020bp09

\begin{abstract}
The purpose of this study was to investigate aspects related to the knowledge of the beneficial effects of practicing physical exercise on certain types of disorders, as well as the level of motivation of subjects to engage in their practice. The study was based on a 7-item questionnaire including the following: 1. Moment of diagnosis of the condition; 2. Doctor's approval for physical activity; 3. Recommended physical activities; 4. Personal motivation for attending physical education classes; 5. Awareness of health benefits; 6. Level of motivation. 7. Awareness of psycho-social benefits. The study was conducted on a sample of 29 first-and second-year students from the three faculties of the "Carol Davila" University of Medicine and Pharmacy in Bucharest, who were medically exempt from physical education classes. Analysing their responses, we have concluded that: most students involved in the study (86\%) have partial medical exemption and the doctors' recommendation for individual and/or group physical activities such as trips, hiking, swimming, medical gymnastics, aerobics; there is a need to design special exercises and exercise structures for students with partial medical exemption, which can be performed in group during the physical education lesson. This is important for including this category of students in regular physical activity throughout the academic year, which would lead them to an active lifestyle; there is also awareness and motivation for involvement in group sports activities, during which socialisation and self-knowledge are obtained spontaneously.
\end{abstract}

Keywords: physical education, students, partial medical exemption,

\section{Introduction}

It is widely recognised that physical activity (PA) is one of the primary needs for human wellbeing, bringing lots of benefits not only to health but also to psychological and social areas.

Rasberry et al. (2011) highlight that regular exercise strengthens the musculoskeletal system, reduces the risk of chronic medical conditions, lowers stress, raises self-esteem and leads to better academic results.

Trudeau and Shephard (2008) also speak about the beneficial influence of school physical activity (curricular and extracurricular) on self-esteem and academic performance. They underline that data suggest that school physical activity (physical education classes or school sport) can and should cover much of the need for physical demands of children and adolescents, and this will have no negative effects on academic achievements, even if the curricular time for the so-called academic subjects is reduced.

In contemporary society, the daily life of ordinary people is gradually becoming devoid of physical challenges. Therefore, specialists, academic institutions, state- and internationallyaccredited bodies have become increasingly concerned about this problem, observing the evolution of the phenomenon, assessing the risks and recommending counter-measures. 
Hallal et al. (2012), analysing global physical activity levels with data for adults (15 years or older) from 122 countries and adolescents (13-15-years-old) from 105 countries, show that $31 \%$ of adults worldwide are physically inactive, the proportions being higher in the American and Eastern Mediterranean countries (43\%) and lower in Southeast Asia (17\%). The same authors observe that inactivity rises with age, is higher in women than in men and is increased in high-income countries.

In the White Paper on Sport, the Commission of the European Communities (2007), speaking about enhancing public health through physical activity, states that lack of physical activity favours increased incidence of overweight, obesity, cardiovascular disease (CVD) and diabetes, with the effect of reducing quality of life, which has a negative impact on both people's lives and the budgets and economies of states.

The European Commission's EU Physical Activity Guidelines (2008) show that children in Europe spend significantly less time in physical activity and more time in sedentary behaviours. It considers this to be an enormous threat, which may be responsible for several physical, metabolic and mental comorbidities during youth and later life. In this context, the Commission emphasises the role of the educational environment in this regard, given that it has been noted that about $80 \%$ of school-age children practice physical activity and sport only in school.

The role of the educational environment, through physical education classes and organized extracurricular physical activity, is also stated by Hallal et al. (2006), who track physical activity from adolescence to adulthood and show how adolescent physical activity can contribute to adult health.

Berenson et al. (1998), addressing physical fitness and CVD risk factors, show that, even if cardiovascular disease events occur most frequently during or after the fifth decade of life, the origins of CVD precursors can be traced back to childhood and adolescence.

Healy et al. (2008) also show that a policy for reducing sedentary behaviour and increasing the time people spend in physical activity will bring substantial health benefits for the society.

Low levels of cardiorespiratory and muscular fitness are associated with global risk factors for the development of cardiovascular diseases (Ortega et al., 2008), increased risk of mortality from coronary diseases, increased abdominal fat, development of arterial hypertension and aortic stiffness (Augustine, 2016; Liu, 2014; Loprinzi \& Pariser, 2013).

Janssen and LeBlanc (2010) confirm the positive influence of exercise on the health of children and young people. The cited authors note that, although the effects are all the more visible as more sports are practised, in the case of subjects with various high-risk medical problems (obesity, high blood pressure), even small amounts of physical activity can be beneficial to health. They also state that exercise intensity should be at least moderate and that the most appropriate exercises are those based on aerobic activity.

Despite the well-recognised benefits of physical activity on enhancing overall health, numerous studies have emphasised that also subjects with different minor medical conditions can benefit from well-designed and properly dosed physical exercise.

Strong et al. (2005) found that physical activity intervention applied for at least 30 minutes 3 times/week, at a sufficiently high intensity to improve aerobic fitness (approximately $80 \%$ of maximal heart rate), could be efficient in reducing blood pressure in youth with mild essential hypertension. Controlled aerobic programmes (2-3 sessions/week for at least 6 weeks) also 
result in improved aerobic and anaerobic fitness in youth with asthma but are not associated with systematic improvements in lung function or exercise-induced bronchoconstriction.

Augustine et al. (2016) report that higher levels of cardiorespiratory fitness can indirectly reduce aortic stiffness through its beneficial effects on traditional and non-traditional CVD risk factors in women with central obesity.

Liu et al. (2014) revealed the potential modifying effect of fitness on blood pressure (BP) trajectory with aging over the lifetime of an adult male. Improving fitness levels can extend the normal range of systolic and diastolic BP, delaying the development of hypertension.

Lamb et al. (2016) showed, for a population of older adults with diabetes, that increased levels of physical activity energy expenditure and cardiorespiratory fitness resulted in reducing clustered cardiometabolic risk and rising the level of moderate-to-vigorous-intensity physical activity, which led to a decrease in systolic blood pressure.

Beunza et al. (2007) found that, for normotensive and hypertensive adults, moderate-tovigorous regular physical activity significantly lowered resting blood pressure and that the risk of developing hypertension was higher for sedentary people.

Arsenault et al. (2010) emphasised that, in any BMI category, inactive participants were characterised by an increased waist circumference, as a marker of abdominal adiposity, compared to active individuals. Physical inactivity and abdominal obesity were both independently associated with an increased risk of future CHD.

Considering all the above, we can observe that the importance of physical activity on human health is undeniable, being revealed by a whole constellation of specialists worldwide. Their findings complement our beliefs about the beneficial effects of physical activity not only on health but also other components of general human wellbeing, such as quality of life, lifelong education, socialisation, based on some of our own previous studies (Tudor \& Tudor, 2013; Tudor et al., 2014). Last but not least, we can support these statements based on our own experience gained over long years of practice as both university physical education teachers and professionals involved in creating and teaching exercise programmes for adults. We strongly believe that the health status of adults is directly related to the physical activity performed in the preliminary stages of development (childhood, adolescence) and is mostly based on school physical activity (the physical education lesson and extracurricular physical activities - leisure PA, school sport).

From the perspective of physical education, a special category of students is represented by those who have partial medical exemption. It is obvious that students who suffer from severe diseases and are forbidden to participate in physical exercise do not fall within the area of concern of the physical education teacher. However, students with partial medical exemption can and should benefit from the practice of well-selected and carefully dosed physical exercise.

In this context, we considered it appropriate to investigate how the importance of physical activity was perceived by students with partial medical exemption. Students with minor medical conditions are a category of persons who require special care from physical education teachers, but they are often neglected. They need to be included in personalised physical activity programmes, especially aerobic exercises (in our opinion), which should be adapted in terms of motor structure, volume, intensity and complexity. Thus, they can safely enjoy the benefits of exercise without feeling embarrassed by the low level of their motor ability compared to that of their colleagues without medical problems. 
This approach meets the recommendations of the European Commission (2015) in the $E U$ Work Plan for Sport 2014-2017. Referring to exemptions from physical education, the Commission recommends exploring "creative ways of accommodating the concerns [...] so as to create the conditions to increase children participation in the activities" (p. 13), adding that "Physical education is a necessary part of school curriculum, and exemptions should only be granted in extraordinary circumstances. In most cases, participation should be ensured with the use of inclusive, differentiated and adapted activities" (p. 13).

\section{Purpose}

This preliminary study is part of a more extensive investigation of the possibilities to include students with partial medical exemption in regular physical education classes using adapted aerobic programmes. The primary purpose of this study was to investigate aspects related to the knowledge of both the beneficial effects of physical exercise on certain types of medical disorders and the level of student motivation to engage in physical activities.

The knowledge resulting from the survey was meant to serve as a starting point for the subsequent steps consisting in creating and applying an original aerobic pilot-programme adapted to the needs of our subjects. This pilot-programme is intended to guide our further experimental research, as part of the doctoral thesis of the first author of this paper.

\section{Assumptions}

We started from the assumption that, given the professional profile of the subjects (medical students), they had information on the positive effects that well-chosen and dosed physical exercises could have on various minor medical conditions.

Extrapolating the results of previous research (Tudor \& Tudor, 2013), we considered that, although many subjects had been medically exempt in pre-university education, if they were aware that exercises were designed to meet their specific needs, they would be motivated to engage in the programme. Moreover, we assumed, also considering the findings of previous research (Tudor et al., 2014), that subjects were aware of the potential psycho-social benefits derived from participating in group sports activities such as aerobics.

\section{Methodology}

\section{Subjects, place and duration of study}

The study was conducted between October 2019 and February 2020 on a sample of 29 firstand second-year students from the three faculties of the "Carol Davila" University of Medicine and Pharmacy in Bucharest, who were medically exempt from physical education classes.

\section{Research organization}

We designed an aerobic pilot-programme adapted to the specific needs of our subjects. The pilot-programme was applied to the selected sample for a period of 5 months, once a week, 
during curricular physical education classes. The initial and final tests were performed for 7 parameters, out of which we will mention only 4 that we consider the most relevant.

\section{Measurements and tests}

We determined the following parameters: weight $(\mathrm{kg})$; chest elasticity $(\mathrm{cm})$; balance measured by the Flamingo Test (modified); vital capacity (CV) - measured by spirometry.

\section{Research methods}

- Questionnaire survey. The questionnaire had a number of 7 items including the following: 1. Moment of diagnosis of the condition; 2. Doctor's approval for physical activity; 3 . Recommended physical activities; 4. Personal motivation for attending physical education classes; 5 . Awareness of health benefits; 6 . Level of motivation. 7. Awareness of psycho-social benefits.

- Experimental method;

- Measurement and test methods;

- Statistical and mathematical method: the data were statistically processed using the Windows Excel program;

- Graphical representation method.

\section{Results}

\section{A) Survey}

The subjects' responses to the questionnaire were summarised and analysed as follows:

1. Moment of diagnosis of the medical condition (How long have you been diagnosed with the condition?) (Figure 1)

Regarding the moment of diagnosis of the disease, most subjects (72\%) responded " 5 or more years", and another $7 \%$ indicated " 3 years". This shows that, during high school, the vast majority of them did not practice physical exercise, at least within the organized framework of physical education lessons. A percentage of $21 \%$ indicated "1 year" as the time of diagnosis.

2. Doctor's approval (Do you have a doctor's approval for physical activity?) (Figure 2)

To this question, $86 \%$ of students said "yes". The other $14 \%$ (4 subjects) did not have the doctor's approval to exercise, which is why they were not included in our aerobic gymnastics programmes and therefore did not participate in the experiment.

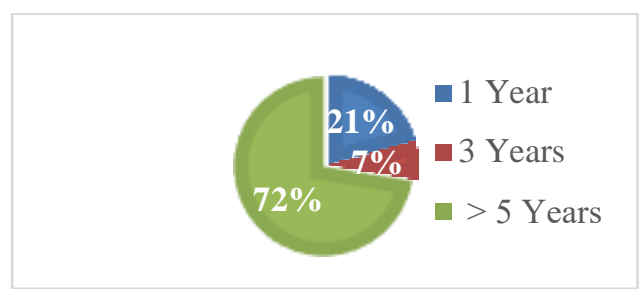

Figure 1. Moment of diagnosis

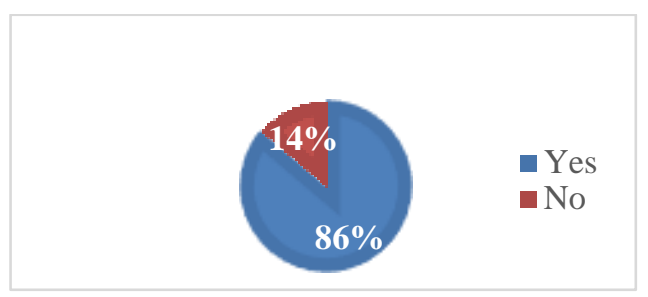

Figure 2. Doctor's approval for physical activity 
3. Recommended physical activities (What type of physical activities have you been recommended?) (Figure 3)

To the third question, the research subjects indicated all options as follows: $45 \%$ had received recommendations for trips and hiking, 34\% for independent, individual or group sports activities (skiing, swimming, medical gymnastics, aerobics), and $21 \%$ for adapted school-organized sports activities.

This distribution of recommendations shows that doctors have considered beneficial an active lifestyle, which involves engaging in various forms of physical activity. The small percentage $(21 \%)$ of recommendations for school-organized sports activities indicates that it is necessary to design lesson plans that include physical exercises adapted in intensity, complexity and duration, with specific methodological indications, in order to meet the needs of students.

4. Level of motivation (To what extent do you want to practice an adapted sports activity within the physical education lessons at the university?) (Figure 4)

The responses to this question indicate the existence of a high level of motivation to attend physical education lessons if they are adapted to their needs (59\% are very willing, while another $17 \%$ have an average level of motivation). Less than a quarter of students have low motivation (21\% are less willing, and $3 \%$ do not want to participate in lessons).

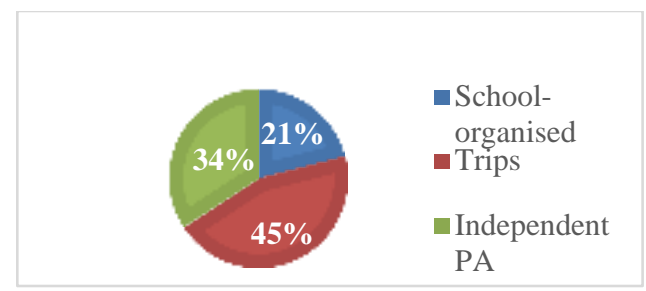

Figure 3. Recommended physical activities

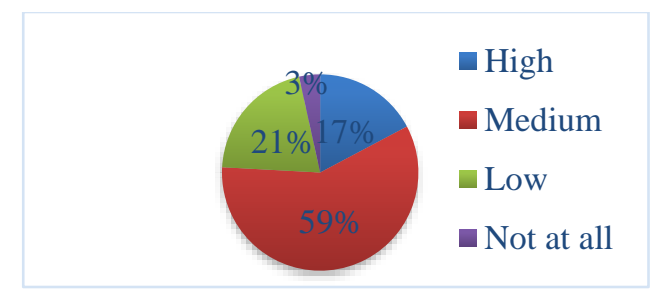

Figure 4. Level of motivation

5. Awareness of health benefits (Do you think the specially-designed aerobic programme has a beneficial effect on your health?) (Figure 5)

Due to the profile of the faculty, medical students are generally considered to be aware of the health benefits of physical exercise. The participants in our survey, even if medically exempt, support this assumption, and their responses to this question have clearly shown it. Almost all (93\%) realise the importance of physical activity for health. Only 7\% (2 subjects) responded in the negative.

6. Quality of motivation (How will you participate in the proposed programme out of conviction or desire?) (Figure 6)

For the majority of participants (62\%), the belief that participation in physical education lessons will bring health benefits prevails. This means that they are engaged in the physical education activity driven first and foremost by this belief. For the others (38\%), the pleasure of practicing physical exercise seems to be a priority. 


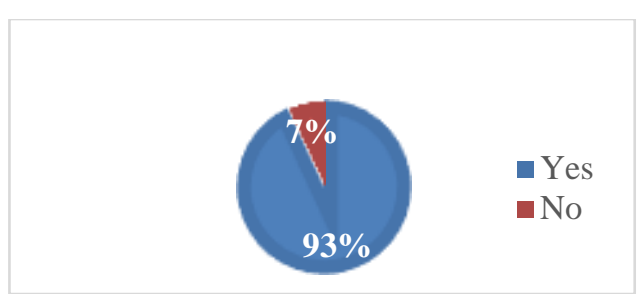

Figure 5. Awareness of health benefits

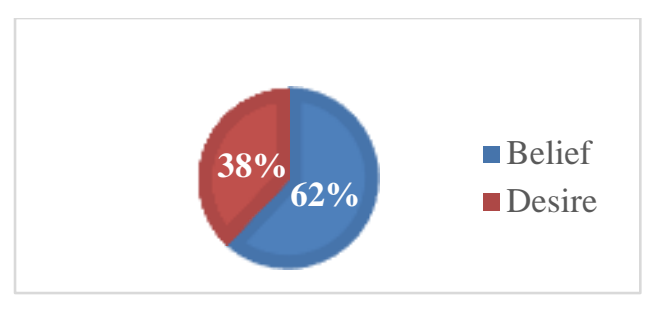

Figure 6. Quality of motivation

7. Awareness of psycho-social benefits (Do you think that participating in aerobics classes will have positive effects on self-knowledge and interpersonal relationships?) (Figure 7)

Most subjects agree that, in terms of socialisation, improvement of peer relationships and self-knowledge, the results can only be good and very good. A small percentage (14\%) are sceptical, probably due to the lack of such an experience.

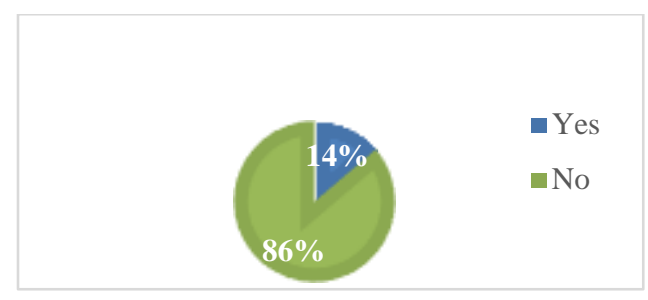

Figure 7. Awareness of psycho-social benefits

\section{B) Pilot-experiment}

All parameters taken into account showed progress from the initial to the final test as a result of the special aerobic exercise programme applied during the pilot-experiment.

The average results recorded in the pilot-experiment and the average progress between the two tests (as absolute values and as percentages) are summarised in Table 1.

Table 1. Average results in initial and final testing and average progress

\begin{tabular}{lcccccccc}
\hline \multicolumn{1}{c}{ Parameter } & \multicolumn{2}{c}{$\begin{array}{c}\text { Weight } \\
(\mathrm{kg})\end{array}$} & \multicolumn{2}{c}{$\begin{array}{c}\text { Chest elasticity } \\
(\mathrm{cm})\end{array}$} & \multicolumn{2}{c}{$\begin{array}{c}\text { Balance } \\
(\text { no. of imbalances })\end{array}$} & \multicolumn{2}{c}{$\begin{array}{c}\text { Vital capacity } \\
(\mathrm{ml})\end{array}$} \\
\hline Test & Initial & Final & Initial & Final & Initial & Final & Initial & Final \\
Average & 57.64 & 57.12 & 4.28 & 4.72 & 6.44 & 6.04 & 2546 & 2716,8 \\
Progress (TF-TI) & \multicolumn{2}{c}{-0.52} & \multicolumn{2}{c}{0.44} & & -0.4 & 170.8 \\
Progress (\%) & $0.9 \%$ & \multicolumn{2}{c}{$10.28 \%$} & \multicolumn{2}{c}{$6.21 \%$} & $6.7 \%$ \\
\hline
\end{tabular}

Regarding the percentage of progress shown in Table 1, the highest influence of the exercise programme appears to be on chest elasticity and vital capacity. This is something we expected, both parameters being directly influenced by aerobic capacity, one of the main targets of aerobic exercise. The next progress, also quite consistent, was recorded for balance, while for weight, the rate of progress was moderate.

In order to determine whether the differences between the average results obtained in the two tests were statistically significant, we used the Student t-Test. The results showed that the differences between the initial and final tests were statistically significant for all parameters (Tables 2, 3, 4 and 5). 
Table 2. Student t-Test for Weight

\begin{tabular}{lcc}
\hline \multicolumn{3}{c}{ t-Test: Paired Two Sample for Means } \\
\multicolumn{1}{c}{ Weight } & Initial & Final \\
\hline Mean & 57.64 & 57.12 \\
Variance & 8.907 & 5.86 \\
Observations & 25 & 25 \\
Hypot. Mean Differ. & 0 & \\
df & 24 & \\
t-Stat & 2.982 & \\
P $(\mathrm{T}<=$ t) one-tail & 0.003 & $<0.05$ \\
Critical t-value one-tail & 1.711 & \\
\hline
\end{tabular}

Table 3. Student t-Test for Chest elasticity

\begin{tabular}{lcc}
\hline \multicolumn{3}{c}{ t-Test: Paired Two Sample for Means } \\
Chest elasticity & Initial & Final \\
\hline Mean & 4.28 & 4.72 \\
Variance & 0.543 & 0.460 \\
Observations & 25 & 25 \\
Hypot. Mean Differ. & 0 & \\
df & 24 & \\
t-Stat & -3.091 & \\
P $($ T $<=$ t) one-tail & 0.002 & $<0.05$ \\
Critical t-value one-tail & 1.711 & \\
\hline
\end{tabular}

Table 4. Student t-Test for Balance

Table 5. Student t-Test for Vital capacity

\begin{tabular}{lcc}
\hline \multicolumn{3}{c}{ t-Test: Paired Two Sample for Means } \\
Vital capacity & Initial & Final \\
\hline Mean & 2546 & 2716.8 \\
Variance & 10608.3 & 9439.3 \\
Observations & 25 & 25 \\
Hypot. Mean Differ. & 0 & \\
df & 24 & \\
t-Stat & -17.256 & \\
P $(\mathrm{T}<=$ t) one-tail & $2.5 \mathrm{E}-15$ & $<0.05$ \\
Critical t-value one-tail & 1.711 & \\
\hline
\end{tabular}

The results of the Student t-Test confirm the validity of the aerobic pilot-programme designed by us, creating the premises for the experiment that will follow, as we explained at the beginning of this paper.

\section{Conclusion}

Considering the responses of medically exempt students to the 7 items of the questionnaire, we can conclude that:

- Most students with medical exemption involved in the study (86\%) have the doctors' recommendation for individual and/or group physical activities such as trips, hiking, 
swimming, medical gymnastics and aerobic gymnastics, being only partly exempt from physical education.

- There is an obvious need to design exercises and exercise structures that can be performed in group during the physical education lesson in order to meet the needs of students with partial medical exemption. This is important for involving this category of students in regular physical activity (mainly physical education classes, but without excluding leisure physical activity) throughout the academic year, thus guiding them towards an active and responsible lifestyle.

- There is awareness and motivation among students with partial medical exemption for involvement in group sports activities (such as aerobics), during which, apart from health benefits, psychological and social gains (such as socialisation and selfknowledge) are obtained spontaneously.

Taking into consideration the findings resulting from the application of the aerobic pilotprogramme, we can conclude that:

- All parameters have shown statistically significant progress from initial to final testing.

- The highest rate of progress has been recorded for vital capacity and chest elasticity, two parameters related to respiratory function; this proves that the choice of adapted aerobic exercise programmes is suitable for students with partial medical exemption, especially those with mild forms of asthma.

- Substantial progress has also been made for balance, showing the potential of this type of exercise over other aspects of motor ability.

- The pilot-programme has also proven its usefulness in reducing bodyweight, even if the effect was less obvious than in other parameters. This was to be expected, the exercise parameters being reduced in order to match the medical condition of students.

- Based on this pilot-experiment, more comprehensive research is needed to find the best ways to involve partially exempt students in regular physical education using adapted aerobic exercise. Thus, it will be possible to identify the most effective exercises, the most suitable dosage of effort, the best forms of organizing lessons and the most appropriate assessment tools.

\section{References}

Arsenault, B. J., Rana, J. S., Lemieux, I., Després, J.-P., Kastelein, J. J. P., Boekholdt, S. M., Wareham, N. J., \& Khaw, K.-T. (2010). Physical inactivity, abdominal obesity and risk of coronary heart disease in apparently healthy men and women. International Journal of Obesity, 34(2), 340-347. https://doi.org/10.1038/ijo.2009.229

Augustine, J. A., Yoon, E. S., Choo, J., Heffernan, K. S., \& Jae, S. Y. (2016). The relationship between cardiorespiratory fitness and aortic stiffness in women with central obesity. Journal of Women's Health, 25(7), 680-686. https://doi.org/10.1089/jwh.2015.5314

Berenson, G. S., Srinivasan, S. R., Bao, W., Newman 3rd, W. P., Tracy, R. E., \& Wattigney, W. A. (1998). Association between multiple cardiovascular risk factors and atherosclerosis in children and young adults. The Bogalusa Heart Study. New England Journal of Medicine, 338(23), 1650-1656. https://doi.org/10.1056/nejm199806043382302 
Beunza, J. J., Martínez-González, M. Á., Ebrahim, S., Bes-Rastrollo, M., Núñez, J., Martínez, J. A., \& Alonso, A. (2007). Sedentary behaviors and the risk of incident hypertension: The SUN cohort. American Journal of Hypertension, 20(11), 1156-1162. https://doi.org/10.1016/j.amjhyper.2007.06.007

Commission of the European Communities. (2007). White Paper on Sport. Brussels. https://eur-lex.europa.eu/legal-content/EN/TXT/?uri=CELEX:52007DC0391

European Commission. (2008). EU physical activity guidelines. Recommended policy actions in support of health-enhancing physical activity. Brussels. https://eacea.ec.europa.eu/sites/eacea-site/files/eu-physical-activity-guidelines-2008.pdf

European Commission. (2015). Expert group on health-enhancing physical activity: EU Work Plan for Sport 2014-2017. Brussels. https://eacea.ec.europa.eu/sites/eacea-site/files/recommendations_pe_at_schools_2015.pdf

Hallal, P. C., Victora, C. G., Azevedo, M. R., \& Wells, J. C. K. (2006). Adolescent physical activity and health. Sports Medicine, 36(12), 1019-1030. https://doi.org/10.2165/00007256-200636120-00003

Hallal, P. C., Andersen, L. B., Bull, F. C., Guthold, R., Haskell, W., Ekelund, U.,\& Lancet Physical Activity Series Working Group. (2012). Global physical activity levels: Surveillance progress, pitfalls, and prospects. Lancet, 380(9838), 247-257. https://doi.org/10.1016/s0140-6736(12)60646-1

Healy, G. N., Wijndaele, K., Dunstan, D. W., Shaw, J. E., Salmon, J., Zimmet, P. Z., \& Owen, N. (2008). Objectively measured sedentary time, physical activity, and metabolic risk: The Australian Diabetes, Obesity and Lifestyle Study (AusDiab). Diabetes Care, 31(2), 369371. https://doi.org/10.2337/dc07-1795

Janssen, I., \& LeBlanc, A. G. (2010). Systematic review of the health benefits of physical activity and fitness in school-aged children and youth. International Journal of Behavioral Nutrition and Physical Activity, 7: 40. https://doi.org/10.1186/1479-5868-7-40

Lamb, M., Westgate, K., Brage, S., Ekelund, U., Long, G. H., Griffin, S. J., Simmons, R. K., Cooper, A., \& Addition-Plus Study Team. (2016). Prospective associations between sedentary time, physical activity, fitness and cardiometabolic risk factors in people with type 2 diabetes. Diabetologia, 59(1), 110-120. https://doi.org/10.1007/s00125-015-3756-8

Liu, J., Sui, X., Lavie, C. J., Zhou, H., Park, Y. M., Cai, B., Liu, J., \& Blair, S. N. (2014). Effects of cardiorespiratory fitness on blood pressure trajectory with aging in a cohort of healthy men. Journal of the American College of Cardiology, 64(12), 1245-1253. https://doi.org/10.1016/j.jacc.2014.06.1184

Loprinzi, P. D., \& Pariser, G. (2013). Cardiorespiratory fitness levels and its correlates among adults with diabetes. Cardiopulmonary Physical Therapy Journal, 24(2), 27-34. https://www.ncbi.nlm.nih.gov/pmc/articles/PMC3691706/

Ortega, F. B., Ruiz, J. R., Castillo, M. J., \& Sjöström, M. (2008). Physical fitness in childhood and adolescence: A powerful marker of health. International Journal of Obesity, 32(1), 111. https://doi.org/10.1038/sj.ijo.0803774

Rasberry, C. N., Lee, S. M., Robin, L., Laris, B. A, Russell, L. A., Coyle, K. K., \& Nihiser, A. J. (2011). The association between school-based physical activity, including physical education, and academic performance: A systematic review of the literature. Preventive Medicine, 52(Suppl 1), S10-20. https://doi.org/10.1016/j.ypmed.2011.01.027

Strong, W. B., Malina, R. M., Blimkie, C. J., Daniels, S. R., Dishman, R. K., Gutin, B., Hergenroeder, A. C., Must, A., Nixon, P. A., Pivarnik, J. M., Rowland, T., Trost, S., \& Trudeau, F. (2005). Evidence based physical activity for school-age youth. The .Journal of Pediatrics, 146, 732-737. https://doi.org/10.1016/j.jpeds.2005.01.055 
Trudeau, F., \& Shephard, R. J. (2008). Physical education, school physical activity, school sports and academic performance. International Journal of Behavioral Nutrition and Physical Activity, 5: 10. https://doi.org/10.1186/1479-5868-5-10

Tudor, I. D., \& Tudor, M. (2013). Leisure sports activities impact on adults' personal development and quality of life. Procedia - Social and Behavioral Sciences, 84, 1090-1094. https://doi.org/10.1016/j.sbspro.2013.06.705

Tudor, I. D., Grigore, V., \& Tudor, M. (2014.) The importance of group sports activities in adult's lifelong education and raising the quality of life. Procedia - Social and Behavioral Sciences, 117, 9-15. https://doi.org/10.1016/j.sbspro.2014.02.170 